\title{
水利工程设计中生态理念的运用研究
}

\author{
高峰 \\ 博斯腾湖管理处 \\ DOI:10.12238/eep.v3i8.947
}

\begin{abstract}
[摘 要] 随着地球环境的不断恶化, “保护地球” 的呼喊声也越来越强烈,生态理念渐渐地开始被世人接 受。水利工程的建设也是人类社会发展的必然趋势,关系到整个社会得到发展,和每个人的日常生活都有 很大的关系。在水利工程设计中, 融人生态理念,是社会发展的需要,是现代化经济建设的重点。基于此, 笔者主要强调了生态理念下对水利工程设计研究的重要性,并结合当前水利工程设计面临的各种困难 和问题,最后提出了几点相关建议。以期为促进水利发展,保护生态环境的可持续发展提供实践性的参考 依据。
\end{abstract}

[关键词] 生态理念; 现代水利工程; 设计研究

中图分类号：D922.38 文献标识码：A

\section{1 生态理念的本质内涵}

生态理念实际上讲求的是一种平衡 关系, 其中传达出来的哲学观就是一种 和谐相处的平衡状态。随着近几年人类 文明的迅速发展, 人类活动对生态环境 的影响是十分强烈的, 从大气污染到土 地盐碱化, 从动植物物种减少到全球温 度变暖, 从泥石流沙尘暴的普遍到洪水 海啸频发, 实际上都是地球生态圈被破 坏导致的。水利工程所牵扯的地理要素 和生物要素都比较多, 水利工程在兴建 过程中, 必然会打破水资源、动植物资源 的自然分布状态，必然会打破原有的平 衡状态, 而生态理念就是要将这种平衡 打破的损失降到最小。简单理解, 生态理 念实际上是在打破旧平衡的基础上建立 起一个新平衡的理念, 旨在将水利工程 设计的生态影响降低到最低。

\section{重要意义}

2 水利工程建设中生态理念的

在社会经济发展的过程中, 需要重 视生态理念的注入, 良好的生态理念能 够有利于社会经济的发展。良好的生态 环境关系到每一个人的身体健康, 也对 人和自然以及社会产生重要的影响。在 水利工程实际发展的过程中, 可以明显 的发现, 不完整的、存在缺陷的生态环境 会对整个社会经济产生重要的影响。生
态环境一旦遭受到破坏, 会严重影响到 社会经济的发展。严重的情况下会出现 泥石流、山体滑坡以及水土流失等严重 的情况。在人类文明不断发展的过程中, 水利工程的建设促进了社会经济的发展, 但是在发展的过程中会受到自然环境的 影响, 存在很多的不可预知的危机。如果 施工人员换在施工的过程没有及时解决 存在的问题, 那么就会产生严重的后果。 想要在水利工程施工建设的过程中合理 的应用生态理念, 就应该重视生态环境 的发展, 重视水利工程在实际发展的过 程中的重要程度, 重视水利工程的实际 运用, 还应该重视生态环境的发展。

\section{3 当前生态水利工程设计工作 中存在的问题}

3. 1水文资料分析利用不全面

基于生态理念的水利工程设计过程 中, 施工地点的水文因素是设计人员和施 工人员都要考虑的重要问题。因为项目周 边的自然环境以及水文条件对水利工程 建设质量和经济效益有着直接的影响。所 以在完善设计方案的同时, 一定要充分调 阅当地的水文资料和数据, 结合大量的数 据经验来保证设计方案的可行性。但是必 须承认的是现阶段我国的水利工程建设 工作, 并没有充分利用和获取水文资料信 息。其次就是设计过程中, 虽然有充分的
水文资料做参考, 但是由于设计人员自身 的专业知识不足或者重视程度不够, 导致 最终的资源利用不充分, 这对后期的设计 方案都有很不利的影响。

3. 2 生态概念的忽视

生态概念在当今社会的应用还很肤 浅。生态观的运用, 不仅要保护现有的生 态环境, 而且要减少水利工程建设中材 料对自然环境的影响, 如采用对地质和 土壤无害的新型材料, 维护动植物的生 态平衡等。水工程设计应摒弃老一套的 方法, 将生态观念上升到自然生态平衡 的高度, 考虑自然对生态系统的调节作 用, 使生态观念在水工程设计中的运用 获得最大效益。

\section{3生态环境监测功能不完善}

生态水利工程设计的一个重要扩展 功能是生态环境监测功能。但目前, 我国 生态水利工程设计的监测功能并不完 善。对生态环境的监测是生态环境保护 的前提和基础, 尤其是对水利工程来说, 必须要在投入使用和运行后, 了解地方 生态环境变化, 以更好地协调后期工作, 发挥出更大的生态环境保护效用。但是, 若缺少了对生态环境的监测, 就会使得 水利工程的生态环境保护成效得不到体 现, 也不能为后期的相关工作开展提供 参考与指导。 


\section{4 生态理念在水利工程设计中 应用不足的解决措施}

4. 1 加强水文环境勘测工作

施工人员在具体施工前要亲自去施 工地点时间考察当地的地质环境和人文 因素, 确保水利设施生态化建设能沿着 理论方向顺利进行, 水力学资料才能够 全面反映河道信息, 才能通过工程设计 充分地实现生态化建设。此外, 在工程建 设的同时能够保护好水资源, 降低水利 工程设计的失误率, 使水利工程更长久 的发展。

\section{2 充分发挥水文工作的作用}

水文工作能够为水利工程设计提供 可靠、有效的水文资料, 通过有效的水文 工作, 能够充分地发挥水文工作的支撑 作用, 为水资源利用和保护提供可靠的 保证。生态理念在水利工程设计中应用 的目的在于保护水资源, 想要将生态理 念更好的应用在水利工程设计中, 需要 以全面、准确以及真实的资料为支撑, 水利工程设计单位必须和水文工作单 位保持良好的合作关系, 在水利主管部 门的协调下, 保证两个部门能够有效的 合作。现阶段, 各种先进的技术和设备 被广泛地应用在各个领域, 水文工作为 了发挥最大的作用, 就必须不断的完善 软件和硬件设施, 充分地利用先进的技 术, 实现对水利工程所有资料的自动 化、全面化采集, 进而为水利工程设计 提供更加全面、详细以及准确的信息资 料, 更好的将生态理念应用在水利工程 设计中。

\section{3 合理运用生态建设材料}

水利工程规划设计中最直接的手段 就是灵活地运用各种各样的生态建设材 料。比如, 可以在水利工程规划设计中有
效地运用网格结构, 通过合理地设置网 格结构, 可以有效增强边坡的稳定性, 同 时可以避免出现水土流失问题, 如植被 加筋技术等都是网格结构建设中常用的 技术, 可以有效提升水利工程建设的生 态价值。又如, 可以在水利工程建设过程 中灵活地运用芦苇、莲花等一些亲水性 植物, 配合生态混凝土砖等环保材料的 应用, 可以构建多样化的防护工程结构, 这样不仅可以对水利工程结构进行美化, 同样可以提升了整体工程的生态环保价 值。

4. 4合理有效地运用生态化理念, 优 化水利工程设计

目前, 在各地区水利工程设计中, 未 能有效贯彻与落实生态化理念, 因此并 未建立统一的设计规范标准, 这种情况 下, 很难对具体工程设计起到科学、合理 的指导, 对生态理念的实现具有制约性。 基于此, 必须从生态环保的层面出发, 找 出水利工程发展特征与生态系统发展需 求不协调的影响因素, 依托先进的科学 技术优势, 实现水资源规划的合理性。这 种情况下, 就要设计人员, 必须提升自身 素养, 提高生态理念应用意识, 充分遵循 自然规律, 优化水利工程设计。同时, 要 平衡好工程建设与生态环境发展的关系, 确保两者能够相互依存, 共同发展。

4. 5 提高水利工程设计人员的综合 素质

在这个高速发展的时代, 我们不缺 乏劳动力, 缺乏的是高尖人才, 只有人才 综合素质提升, 我们才能使设计工作提 高普遍质量, 将生态理念落实到位。水利 工程生态建设的设计是极度需要高尖人 才的领域, 水利工程建设需要高素质设 计人才对目前的水利工程出现的生态问
题或是当地生态环境的情况进行实地考 察、大数据分析和策略设计等。高素质 的专业设计人才可以将生态理念更好地 融合到水利工程中。引进高素质人才、 提高现有人才素质还可以提高整个水利 工程团队的专业技术水平, 提高团队的 工作效率, 加大团队凝聚性, 促使生态理 念的建设工作获得更好的成绩。

4. 6 加强设计人员对生态理念的重 视程度

首先, 提高设计者的生态保护意识, 实现生态理念与水利工程设计的有机结 合。其次, 逐步改变设计师的水利工程设 计理念, 在传统水利设计的基础上, 适当 创新和完善设计理念和方法。最后, 加强 生态理念在水利工程设计中的应用, 在 设计水利工程的过程中, 设计者不仅要 考虑直接的经济效益, 还要考虑生态环 境的可持续发展。

\section{5 结语}

由于近几年来, 我国对生态环境保 护的重视程度越来越高, 基础设施建设 的生态效益在项目的评价分析指标中所 占的比重也越来越大。水利工程建设作 为基础设施建设的重头戏, 其生态理念 的应用就显得格外重要。

\section{[参考文献]}

[1]余红.生态理念在水利工程设 计中的重要性及应用实践 [J]. 治 淮,2019,(02):38-39.

[2]陈维江.试论水土保持生态修复 在水利工程设计中的应用 [J]. 低碳世 界,2019,9(02):92-93.

[3]常全月. 论述水利工程设计 中如何运用生态理念 [J]. 建筑发 展,2017,1(03):417-418. 